\title{
A Multidisciplinary Approach in Treating a Patient with Unilateral Cleft Alveolus
}

Das D

Department of Pedodontics and Preventive Dentistry

Kalinga Institute Of Dental Sciences

Bhubaneswar, Odisa

India

\begin{abstract}
Any type of aesthetic correction in dental practice is always a challenging task, especially when it is complicated with cleft lip and alveolus. Careful examination and correct decision making at early stage of treatment and multi disciplinary approach is always necessary for long term success.

This paper described a multidisciplinary approach in managing a 19-yearold female patient with unilateral cleft alveolus impacted maxillary canine, missing lateral incisor and hypoplastic central incisor by surgical, orthodontic and prosthodontic means. The impacted canine was surgically exposed and orthodontic traction given to bring it into the normal alignment. The missing lateral incisor was replaced by a fixed bridge with a ceramic gingival fixed prosthesis to manage alveolar cleft. At the same time the hypoplastic defect of central incisor was hidden by the full coverage retainer used for the bridge abutment on the tooth.
\end{abstract}

Corresponding Author

Dulal Das

Department of Pedodontics and Preventive Dentistry

Kalinga Institute Of Dental Sciences

Bhubaneswar, Odisa

India

Email: drdulaldas@gmail.com

\section{KEY WORDS}

Citation

Alveolar cleft, gingival prosthesis, impacted canine, orthodontic extrusion

Das D. A Multidisciplinary Approach in Treating a Patient with Unilateral Cleft Alveolus. Kathmandu Univ Med J 2013;42(2):171-174.

\section{INTRODUCTION}

Cleft patients have markedly higher frequency of congenitally missing and impacted permanent teeth as compare to the normal population. ${ }^{1,2}$ The incidence of congenitally missing permanent lateral incisors within the alveolar cleft is between 35 and $60 \%$ and the frequency of these congenitally missing teeth are higher in girls than in boys. $^{3-5}$ It is reported by the many researchers that most frequently missing teeth in cleft patients are the maxillary lateral incisors in the cleft region and the maxillary second premolars outside the cleft region. ${ }^{1}$

Maxillary canines are the most commonly impacted teeth. ${ }^{6,7}$ It occurs in approximately two percent of the normal population and is twice as common in females than in males. ${ }^{8,9}$ Again its incidence in the maxilla is more than twice that in the mandible. ${ }^{9}$ Patients with alveolar clefts had a 20 -fold increased risk for canine impaction. ${ }^{10}$ In this reported case a comprehensive multidisciplinary approach was undertaken to manage a unilateral cleft alveolus with congenitally missing maxillary lateral incisor and canine impaction of same side in a 19 years old young girl.

\section{CASE REPORT}

A 19 year-old girl was reported in a dental clinic for the unpleasing smile (Fig 1A)because of her unilateral cleft lip and alveolus of left side of maxilla in which surgical correction done 12 years back. On clinical examination (Fig 2A) it was revealed that she had missing maxillary left lateral incisor (22), hypoplastic left central incisor (21) and retained maxillary deciduous left canine (63). The clinical examination also revealed Angle Class I molar relationship with deep bite (Fig 2A) and crowding in lower anterior segment. The permanent left maxillary canine (23) was not visible in the arch. 

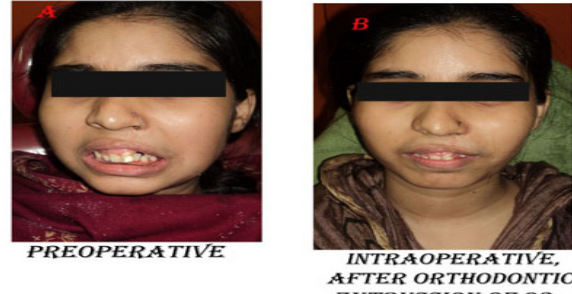

AFTER ORTHODONTIC

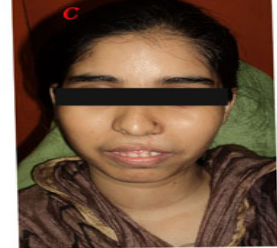

INTRAOPERATIVE, AFTER REMOVABLE PROSTHESIS FOR 2

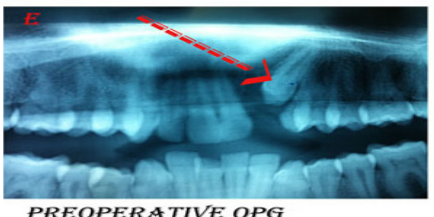

PREOPERATIVE OPG

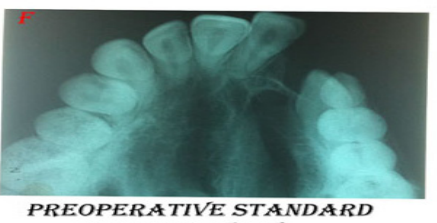

OCCLUSAL VIEW

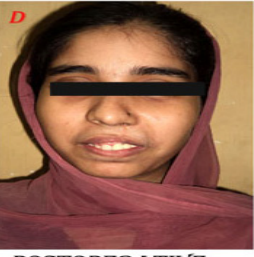

POSTOPERATIVE,
AFTER FLXED PROSTHESIS IN 22

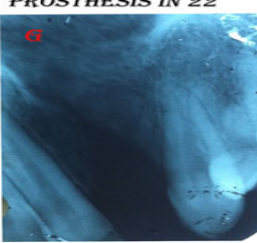

POSTOPERATIVE

Figure 1. A Preoperative profile view, B Intraoperative profile view, after orthodontic extrusion of 23, C Intraoperative profile view, RPD for missing 22. D Postoperative profile view, FPD with gingival prosthesis is cemented, E Preoperative OPG, F Preoperative standard occlusal view, G Postoperative IOPA showing 23.
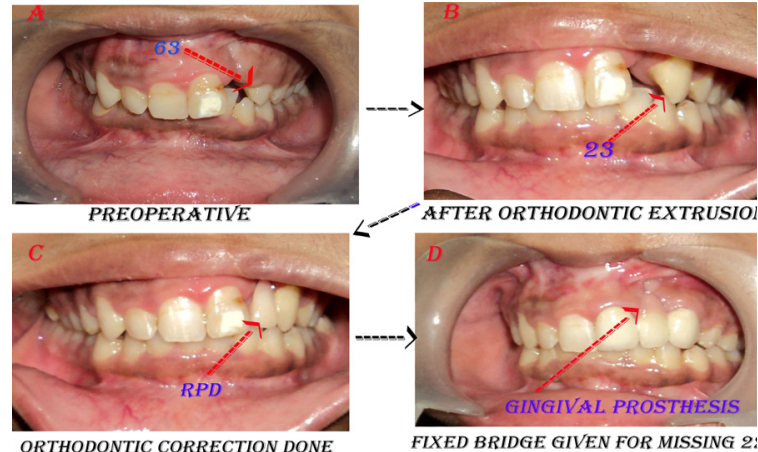

FIXED BRIDGE GIVEN FOR MISSING 2 Figure 2. A Preoperative intraoral view, B After orthodontic extrusion of 23, C After orthodontic correction and RPD in place, D Postoperative intraoral view showing FPD with gingival prosthesis for 22 .

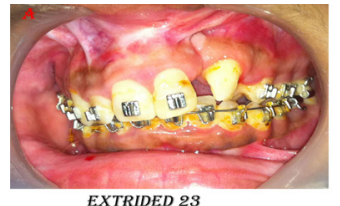

EXTRIDED 23

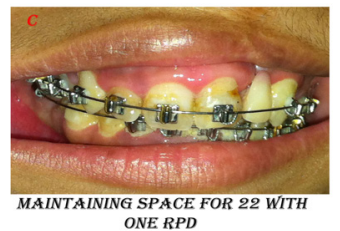

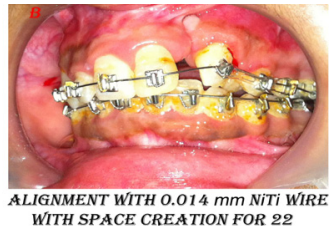

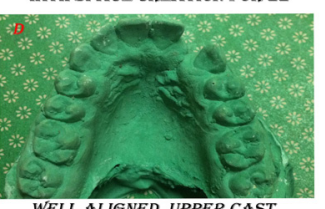

WELL ALIGNED UPPER CAST
Figure 4. A Intra oral view after orthodontic extrusion of 23, B Alignment done with $0.014 \mathrm{~mm} \mathrm{NiTi}$ wire and space created for 22, C Maintaining space with RPD, D Cast shows well aligned upper arch.

The radiological examination (OPG) showed (Fig 1E) that the 23 was impacted, situated almost vertically and the crown was directed obliquely mesially into the arch. A clear bony defect (Fig 1F) was observed along the cleft in upper standard occlusal radiograph.

\section{Treatment}

The objective of treatment was to provide a esthetic profile by preparing an adequate space for an ideal pontic with gingival prosthesis for missing 22 with bony defect and

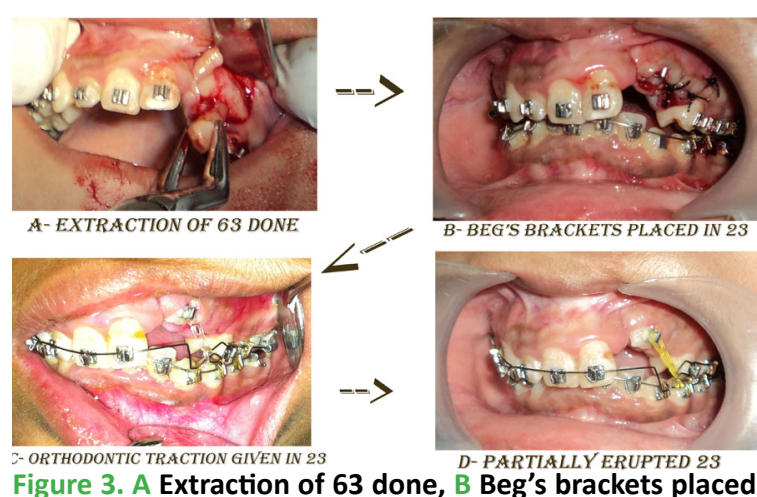

in 23, C Orthodontic traction given in 23, D Partially extruded 23.
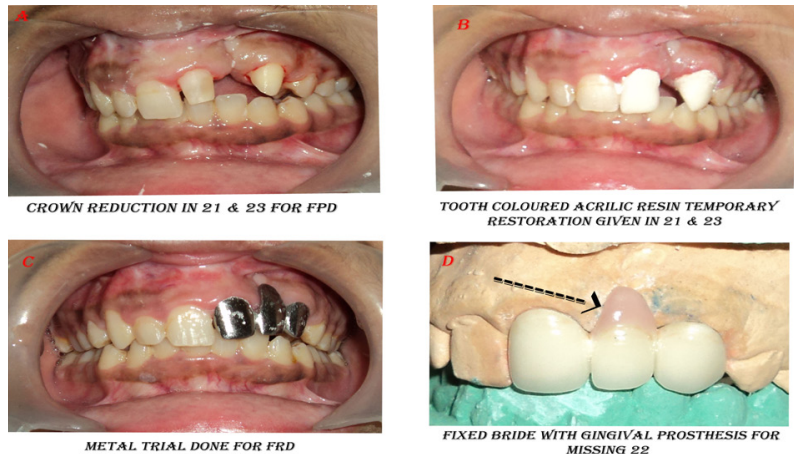

Figure 5. A Crown reduction done in 21 and 23, B Temporary restoration given in 21 and 23, C Metal trial done for FPD, D Fixed bridge with gingival prosthesis for missing 22 .

proper positioning of the impacted 23 into the arch to obtain a well alignment .

As because the lower teeth were in crowding condition with a stiff curve of spee, so treatment was also planned for crowding and deep bite correction in the lower dental arch.

After necessary pre surgical investigations decision was made to perform orthodontic extrusion of impacted 23 by surgical exploration of the crown of 23. Begs' brackets 
were placed in upper and lower teeth pre-surgically. A full thickness muco-periosteal flap was elevated from 21 to 24 region under local anaesthesia, extraction (Fig 3A) of retained 63 was done and crown of 23 was discovered just after removing a shell of bone from labial cortex. A Begs' orthodontic bracket was placed on 23 and suturing done (Fig 3B).

As the suture removal done after seven days, orthodontic traction was started with the help of an E-chain and arch wire (Fig 3C, D). A $0.014 \mathrm{~mm} \mathrm{NiTi}$ wire was used in lower ach for the correction of crowding. Within seven months orthodontic extrusion of 23 was completed (Fig 4A) and angulation with vertical axis was corrected by the use of two E-chains (Fig 4B) along the arch in two halves of the edentulous space and by that way sufficient space was created for future 22 (pontic). The deep bite was corrected by incorporating anchorage bend $\left(25^{\circ}\right)$ in lower arch wire. After orthodontic correction of malocclusions, all brackets were removed and a modified Howley appliance (removable plate with attached acrilic lateral incisor for to hold the created space for 22) was given for six months as a retentive device. At the end a removable partial denture replacing 22 was given to the patient for next six months (Fig 4C) for better tissue adaptation.

At the end of six months vitality testing for 23 revealed positive response and an IOPA radiograph showed normal peri radicular area (Fig 1E). A fixed bridge was planned taking 21 and 23 as abutments for missing 22 and a ceramic gingival replacement was attached with the pontic for alveolar defect correction (Fig 5A, B, C and D). The extracoronal full coverage porcelain fused to metal restoration on 21 helped to hide the hypoplastic defect (Fig 2D) .

\section{DISCUSSION}

Maxillary permanent canines are important for an attractive smile and are also essential for a functional occlusion. Offering a pleasing esthetic appearance in a patient with cleft lip and alveolus is one of the toughest jobs in dental practice. Many a times over retention of deciduous canine makes the situation more difficult by impacting succedenious permanent canine. Surgical exposure of the impacted canine and the use of fixed orthodontic appliances is the most frequently used treatment alternative as long as the tooth position is favourable. Various methods have been used for bringing the canine into proper alignment. Fournier et al have proposed the use of a removable plate. ${ }^{11}$ Becker and Zilberman have recommended the use of a flexible palatal arch slotted into horizontal, soldered, palatal tubes on the molar bands of any type of fixed multibonded appliance. ${ }^{12}$ Jacoby has suggested his ballista spring to direct a palatal-occlusal force from the buccal side. ${ }^{13}$ In this reported case the extrusion was done with the help of an E-chain and an arch wire.
Considerable amount of bony defects in anterior region can be easily managed by prosthetic approach. A fixed gingival prosthesis (ceramic) or removable gingival prosthesis (acrylic) can eliminate invasive surgical procedure. ${ }^{14} \mathrm{~A}$ fixed prosthesis gives the patient significant comfort and peace of mind, as well as self-confidence (because the prosthesis is always present). However, its application may be limited to certain clinical situations where oral hygiene is manageable, the desired esthetic result is achievable or esthetics are not critical, and a fixed prosthesis is already planned for the immediate area. ${ }^{14} \mathrm{~A}$ fixed coral pink coloured ceramic gingival prosthesis with the pontic replacing the missing 22 was planned in this reported case. The bony deficiency at the alveolar cleft was managed by the ceramic gingival prosthesis which was very aesthetc ,highly polished and easy to maintain.

The total treatment time was two years and post operative followup was done for another one year. Orthodontic extrusion took almost seven months which was almost one third of the total treatment span. During the treatment step by step correction of deep bite and lower incisors crowding were done in conventional technique.

\section{CONCLUSION}

Aesthetic correction of a patient with cleft lip and alveolus in is always a challenging job especially when the situation is complicated with over retained deciduous tooth and impacted permanent tooth. In this reported case a combination of orthodontic, prosthodontic and surgical technique were advocated to get the ultimate pleasing smile. Only multidisciplinary approach and careful evaluation in each and every step of treatment is mandatory for this kind of long term success. As because the cleft patients are belong to very low self esteemed group so least invasive treatment modality should need to be advocated for better tolerance.

\section{REFERENCES}

1. Olin WH. Dental anomalies in cleft lip and palate patients. Angle Ortho. 1964;64:119-123.

2. Russell KA, McLeod CE. Canine eruption in patients with complete cleft lip and palate. Cleft Palate Craniofac J 2008 Jan;45(1):73-80.

3. Peterson's Principles of Oral and Maxillofacial Surgery. Vol 1: 861.

4. Mattheeuws N, Dermaut L, Martens $\mathrm{G}$. Has hypodontia increased in Caucasians during the 20th century? A metaanalysis. Eur J Orthod 2004;26:99-103.

5. Brook AH. Variables and criteria in prevalence studies of dental anomalies of number, form and size. CommunityDent Oral Epidemiol $1975 ; 3: 288-293$.

6. Ngan P, Hornbrook R, Weaver B (2005). Early timely management of ectopically erupting maxillary canines. Semin Orthod 11:152-163.

7. Bishara SE (1992). Impacted maxillary canines: a review. Am J Orthod Dentofacial Orthop 101: 159-171. 
8. Cooke J, Wang HL (2006). Canine impactions: incidence and management. Int J Periodontics Restorative Dent 26: 483-491.

9. Proffit WR, Fields HW, Sarver DM (2007). Contemporary Orthodontics. (4thedn). St. Louis: Mosby.

10. Yavuz MS, Aras MH, Buyukkurt MC, Tozoglu S. Impacted mandibularcanines. J Contemp Dent Pract 2007 8: 78-85.

11. Fournier A, Turcotte JY, Bernard C. Orthodontic considerations in the treatment of maxillary impacted canines. Am J Orthod 1982;81:236239.
12. Becker, A, Zilberman Y. A combined fixed-removable approach to the treatment of impacted maxillary canines. JClin Orthod 1975;9:162169.

13. Jacoby H. The "ballista spring" system for impacted teeth.Am J Orthod 1979;75:143-151.

14. Ba rzilay I, Tamblyn I.Gingival Prostheses - A Review. J Can Dent Assoc 2003; 69(2):74-8. 